\title{
PERIODISTAS, PERIODISMO Y HEGEMONÍA EN LA UP
}

Gustavo González Rodríguez. 


\section{GUSTAVO GONZÁLEZ RODRÍGUEZ}

Periodista y magíster en Comunicación Política de la Universidad de Chile. Fue profesor asociado de la misma universidad hasta su jubilación, en 2012. Dirigió la Escuela de Periodismo de la Universidad de Chile entre 2003 y 2008. Trabajó varios años para la Agencia Inter Press Service en Ecuador, Italia, Costa Rica y Chile. Fue presidente de la Asociación de Corresponsales de Prensa Extranjera en Chile a comienzos de la década de los noventa. 


\section{PERIODISTAS, PERIODISMO Y HEGEMONÍA EN LA UP}

"Hablar de revoluciones, imaginar revoluciones, situarse mentalmente en el seno de una revolución, es hacerse un poco dueño del mundo. Quienes hablan de una revolución se ven llevados a hacerla".

Alejo Carpentier, El siglo de las luces.

No es lo mismo reflexionar, escribir e historiar sobre el periodismo que sobre los periodistas en la Unidad Popular. Hay que evitar, igualmente, la tentación de subordinar el análisis del paisaje comunicacional de aquellos años a algunos íconos, erigidos con el tiempo en modelos de periodistas y de periodismo. Tampoco es recomendable caer una vez más en un reduccionismo fácil que conjuga el pluralismo y la libertad de expresión solamente a la luz de la distribución de la propiedad de los medios.

Sin embargo, hay que incursionar necesariamente en esos temas, y buscar a la vez antecedentes que amplíen el análisis y contribuyan a reconstruir el papel de los periodistas durante "los mil días de Allende", con la pretensión de aportar, desde una mirada crítica, algo nuevo a lo mucho que ya se ha escrito al respecto.

Los periodistas, proclamados a veces con generosidad como los historiadores del día a día, no solo fuimos testigos y cronistas de la experiencia de la Unidad Popular. Fuimos igualmente, y sobre todo, protagonistas de un proceso que, mirado con la perspectiva de cincuenta años, puso de lleno en el debate político la cuestión de la hegemonía, que desde entonces se ha hecho recurrente, aunque a menudo manoseada, en los ejercicios teóricos sobre el poder.

Desde esta perspectiva, es insuficiente trazar una línea vertical para alinear fácilmente a los periodistas y a los medios en bandos a favor o en contra del gobierno de Allende y su programa. El asunto es más complejo si se quiere conjugarlo en claves sociales y culturales que remitan a una noción comprehensiva del espacio público y de las condiciones en que se desenvolvió la lucha de clases hasta el 11 de septiembre de 1973.

Establecido este desafío analítico, el presente artículo recurrirá a las necesarias referencias bibliográficas, a recuerdos e inquietudes personales del autor, además de testimonios de otros actores del quehacer político-periodístico de aquellos años, aunque previamente será menester trazar o reconstruir contextos, corriendo el riesgo de que, a primera vista, algunos aparezcan "fuera de contexto". 


\section{CONTEXTO 1: HABLAR DE REVOLUCIÓN}

"Quienes hablan de una revolución se ven llevados a hacerla", escribió Alejo Carpentier en su magistral recorrido literario de ida y vuelta desde La Habana a París bajo el iluminismo de libertad, igualdad y fraternidad, pero también de terror y guillotina. La referencia es válida, ya que hasta los años sesenta del siglo pasado, la palabra no estaba demonizada como hoy. Baste recordar que Eduardo Frei, acompañado por la Patria Joven, levantó su triunfante candidatura presidencial de 1964 bajo el lema de "revolución en libertad".

El gobierno de Frei significó un paso adelante en la modernización de Chile, particularmente por su reforma agraria, que requirió una reforma constitucional sobre el derecho de propiedad, aprobada con el respaldo de la izquierda en el Parlamento. Aunque declarados enemigos de la revolución cubana, los jóvenes democratacristianos levantaron un discurso anticonservador y antimperialista que los llevó a acompañar jornadas de solidaridad con Vietnam y, sobre todo, a iniciar la reforma en la Pontificia Universidad Católica en 1967, con el emblemático lienzo "Chileno: El Mercurio miente". Este último, un dato relevante para el periodismo.

Siempre en la terminología de los años sesenta, la Democracia Cristiana era un partido pluriclasista, y esta visión, sostenida sobre todo por el Partido Comunista, se mostró certera en los últimos años del sexenio de Frei, cuando la ostensible inclinación a la derecha del gobierno gatilló la disidencia encabezada por Rodrigo Ambrosio, que dio nacimiento, en mayo de 1969, al Movimiento de Acción Popular Unitaria (MAPU), que contribuyó a ensanchar el abanico político e ideológico de la Unidad Popular.

La "revolución en libertad" naufragó. La promesa de la transformación se encarnó entonces en la amplia alianza de partidos marxistas, socialdemócratas y cristianos que llevaron a Allende al triunfo electoral el 4 de septiembre de 1970. En octubre de 1971 se fundó la Izquierda Cristiana (IC) como otra disidencia democratacristiana, que también recogió cuadros procedentes del MAPU contrarios a la opción marxista-leninista adoptada por ese partido.

"Destacamento revolucionario de inspiración cristiana y humanista". Con esta definición programática, la IC se sumó a los objetivos de cambios profundos de la sociedad y del Estado que se proponía la UP. Ya no se trataba solo de hablar de revolución, sino que se sentía que estaban al alcance los medios para llevarla a cabo. Ya no era la propuesta reactiva de una "revolución en libertad" como un eslogan de alcance continental que pretendía poner diques al ejemplo de la revolución cubana.

Las proclamas de "la vía chilena al socialismo" y de "una revolución con vino tinto y empanadas" ponían el acento en el carácter no armado de la conquista del poder, aunque en términos de la abolición del sistema capitalista y del cambio del 
Estado, los desafíos se seguían teorizando desde la ortodoxia marxista-leninista. No podía ser de otra manera en una alianza como la UP, cuyos dos partidos principales, el Socialista y el Comunista, se identificaban con esa definición, que sumó también con aires innovadores al MAPU.

Hablar de la revolución pasó a ser entonces un ejercicio recurrente en las militancias políticas y en los debates entre estas. Siempre invocando a Lenin, y con un amplio repertorio de citas, se podía discutir si el programa de la UP conduciría efectivamente al socialismo o si significaba solo la materialización de una revolución democrático-burguesa y antimperialista en que el socialismo sería la tarea de una siguiente fase.

Estas polémicas sobre el carácter reformista o revolucionario del proceso fueron gatilladas desde dentro y fuera de la UP. Desde fuera de la alianza de gobierno, por la influencia que alcanzaba el Movimiento de Izquierda Revolucionaria (MIR) entre los sectores que este partido llamaba "los pobres de la ciudad y del campo", lo cual instalaba a su vez otro vector de confrontaciones teóricas en torno al papel de vanguardia revolucionaria que la ortodoxia marxista le asignaba al proletariado.

Textos clásicos como el Qué hacer y El Estado y la revolución fueron convertidos en manuales sacralizados. Revolución en la revolución del francés Régis Debray pasó a ser un recetario más que una sistematización de la teoría del foco guerrillero. Las lecturas del mayo del 68 podían apuntar en uno u otro sentido en una dicotomía excluyente de reformismo y ultrismo.

Este artículo no pretende dar una visión exhaustiva de las diversas posiciones y sus enfrentamientos, que se desbordaron muchas veces en descalificaciones fáciles de los contradictores. Lo importante, para nuestros propósitos, es adelantar que los periodistas participaron desde su profesión u oficio en las definiciones a ratos polarizadas dentro de la izquierda y lo hicieron desde diversas trincheras; desde las militancias partidarias a la academia, desde sindicatos a asambleas abiertas, desde el panfleto o la trinchera hasta el sesudo análisis; desde el enfoque del simple reporteo hasta el reportaje interpretativo.

Los trabajadores de la prensa identificados con la izquierda no estuvieron ajenos a los grandes momentos ni a las sucesivas crisis del gobierno de Allende. La diversidad de la UP, que fue su gran fortaleza para construir la mayor alianza político-social de Chile en el siglo XX, devendría en debilidad cuando la rearticulación opositora y la agresión externa orquestada por Washington no solo evidenciaran sus falencias, sino también la falta de respuestas con la celeridad que exigían los acontecimientos.

Tomás Moulian hace en su libro Fracturas un buen relato analítico de la concatenación de hechos que debilitaron a la coalición de gobierno, partiendo por la falta de una dirección única en la UP, el obligado protagonismo de Allende como conductor y árbitro, el fracaso de un acuerdo con la DC en 1971 y el posterior 
desplazamiento de lleno de este partido hacia la derecha, que fue conquistando para una causa opositora radicalizada a los sectores medios. De cara a la contingencia, la supervivencia de la "vía chilena al socialismo" se empantanó en líneas estratégicas divergentes de los partidos de la UP, e incluso con quiebres al interior de sus orgánicas, en especial las de inspiración marxista-leninista (Moulian, 2006).

\section{CONTEXTO 2: LA CUESTIÓN DE LA HEGEMONÍA}

En 1971, el profesor Osvaldo Fernández, filósofo y militante comunista, publicó la primera antología de escritos de Antonio Gramsci editada en Chile (Fernández, 1971) ${ }^{1}$. El pensador italiano era hasta entonces un virtual desconocido en los círculos políticos. Un año antes, otro intelectual comunista, Yerko Moretic, había publicado un profundo estudio sobre Mariátegui que rescató el influjo gramsciano en la obra del dirigente revolucionario peruano (Moretic, 1970)2.

Moretic, crítico literario y profesor de castellano, dio en alguna medida continuidad en este libro a su defensa del realismo en tanto propuesta literaria de contenido social asentada en América Latina, que constituía, a su modo, una superación del realismo socialista impuesto por el estalinismo.

Los primeros escritos de Gramsci divulgados en Chile por Fernández fueron, en su esencia, un emplazamiento a los resabios estalinistas que, si bien ya no figuraban en los discursos, sí seguían presentes en prácticas dogmáticas y burocráticas de la izquierda adscrita al marxismo-leninismo, sobre todo en la aplicación del llamado centralismo democrático. El esquema maniqueísta de la Guerra Fría fue otro ingrediente a favor de la persistencia de esas prácticas.

(Resulta sintomático que en el conglomerado de pretendidos refutadores e "intérpretes" de Gramsci, surgidos en la derecha sobre todo tras la debacle de los socialismos reales, no solo se recurra a tergiversaciones burdas de su pensamiento, sino que además se haga con una retórica descalificatoria que no tiene nada que envidiarle a la virulencia de los discursos estalinistas de hace unos setenta años ${ }^{3}$ ).

1. En 2016 la obra fue reeditada por la Universidad de Valparaíso a través de la Editorial Popular La Pajarilla, con un prólogo actualizado del autor.

2. El autor falleció tempranamente, a los 44 años, el 11 de julio de 1971, el mismo día de la nacionalización del cobre.

3. Los ejemplos al respecto son numerosos. Ver un artículo de Axel Kaiser, director ejecutivo de la Fundación para el Progreso, sobre el estallido social, titulado "El triunfo de Gramsci", en: https://www.df.cl/noticias/opinion/columnistas/el-triunfo-de-gramsci/2019-12-18/190902. html 
Lo cierto es que poco o nada se citaba a Gramsci en los debates al interior de la izquierda chilena durante la UP. Sin embargo, se fueron incubando en esos años grupos de seguidores de ideas clave del gran revolucionario italiano. Su "traducción" del marxismo como la filosofía de la praxis, sus formulaciones acerca del "bloque histórico", sus definiciones acerca del papel de los intelectuales y el concepto de hegemonía pueden ser vistos hoy, a cincuenta años de distancia, como cuestiones que estuvieron en el trasfondo de las sucesivas crisis que enfrentaron el gobierno de Allende y los partidos de izquierda no solo hasta el golpe de 1973, sino también en los debates que en los primeros años del exilio buscaban adjudicar culpas por el cruento fin de la "vía chilena al socialismo".

No se necesita extremar las teorizaciones para sostener que esas cuestiones rondaron también, como preguntas a veces sin respuesta o de comprensión parcial, a las políticas comunicacionales del periodo de la UP. Hay que decirlo en plural, porque obviamente no hubo una sola política comunicacional en el Gobierno y en la alianza gubernamental, en una nueva demostración de una diversidad que era riqueza y, al mismo tiempo, debilidad.

Es ya un lugar común decir que el 4 de septiembre de 1970, "la UP conquistó el gobierno, pero no conquistó el poder". Este aserto se suele conjugar con la cuestión militar, establecida como una carencia tanto teórica como práctica de los partidos de izquierda, en algunos por haber confiado ingenuamente en la vocación constitucional de las Fuerzas Armadas, en otros, como el MIR, por no haber construido destacamentos militares propios en una dimensión acorde con su discurso de inevitabilidad del enfrentamiento.

La cuestión de las capas medias fue otro asunto no resuelto desde el punto de vista de la conquista del poder, en la clave pacífica del proyecto de la UP. Las contingencias y desencuentros que se dieron al respecto en el interior de la alianza gubernamental están sistematizados por Moulian y no corresponde aquí profundizar en ello (Moulian, op. cit.).

Nos remitimos igualmente a Moulian para apuntar como otro tema sin resolución la cuestión económica, vinculada al punto anterior en términos tanto de los caminos elegidos para construir el área de propiedad social como de las relaciones con la pequeña y mediana empresa y con sectores laborales de la producción y la burocracia.

A la luz de esta enumeración, que podría extenderse a otras esferas — sobre todo la cultural y comunicacional—, resulta necesario recurrir a Gramsci para desembocar en el tema central: la cuestión de la hegemonía.

El proletariado, planteó Gramsci, como conductor de "las clases subordinadas" debe articular "el bloque histórico" capaz de llevar a cabo la revolución. Este proceso 
implica ganar al vasto conglomerado de sectores sociales explotados por la gran burguesía. La apropiación del gobierno, el control del aparato del Estado, incluso neutralizando o sometiendo a su brazo militar, puede convertir a este bloque social en dominante, pero para concretar la revolución se requiere, además y sobre todo, que sea dirigente. $\mathrm{O}$ sea, debe convencer y conquistar a la sociedad en su conjunto en favor de sus ideas de igualdad, transformación y justicia.

Dicho de manera esquemática, la hegemonía consiste, por tanto, en generar esta confluencia de la condición dominante con la condición dirigente. La tarea de los revolucionarios es asumir la filosofía de la praxis con el imperativo de no solo interpretar el mundo, sino de transformarlo, según la célebre tesis de Carlos Marx.

Gramsci y sus seguidores influyeron en una relectura de los clásicos que supo nutrirse tanto de las condiciones nacionales como del protagonismo que correspondía a los países periféricos, con sus proyectos de liberación nacional, identificados entonces bajo el rótulo de Tercer Mundo. Una propuesta muy válida dentro de la polarización de la Guerra Fría, que no apostaba a la neutralidad, sino a una propuesta socialista de perfil propio, latinoamericano, en nuestro caso.

Luis Alberto Vásquez, otro joven profesor de filosofía, impartía en los inicios de los años setenta un curso para estudiantes de Periodismo y del Pedagógico acerca de Las tesis sobre Feuerbach, que hacía una sugerente síntesis de la filosofía de la praxis con la idea del hombre nuevo propuesta por Ernesto Che Guevara en su obra acerca del socialismo en Cuba, como otro aporte a la gran idea de la transformación.

No se trata en Gramsci de una transformación restringida a las condiciones materiales o de la infraestructura, sino que también abarcaba la superestructura. Por tanto, la cuestión cultural va ligada estrechamente a la cuestión de la hegemonía. Es aquí donde el gran revolucionario italiano hizo una de sus mayores contribuciones, al escribir sobre el papel de los intelectuales en tanto pensadores y agentes de la política, ya no recluidos en círculos de iniciados por encima de la sociedad, sino actores conscientes en la lucha de clases. Por tanto, intelectuales orgánicos. Las clases dominantes tuvieron siempre sus intelectuales orgánicos. En las clases subordinadas, estos deben representar la síntesis de la teoría de la praxis, de conquista de la infra y la superestructura, para alcanzar la hegemonía.

Para muchos estudiosos de la filosofía política, puede resultar burdamente esquemática la descripción del pensamiento gramsciano intentada aquí. Transmitidas las excusas correspondientes, interesa plantear, como tema de debate, el papel cumplido por los medios en la disputa por la hegemonía durante la UP y postular que los periodistas estuvieron también llamados a ser parte de los intelectuales orgánicos en esta lucha. 


\section{CONTEXTO 3: LA FORMACIÓN DE LOS PERIODISTAS}

En 1970, para el triunfo electoral de Salvador Allende, las dos escuelas de periodismo más antiguas del país — de la Universidad de Chile y la Universidad de Concepción - recién cumplían diecisiete años de vida. En el ejercicio de la profesión u oficio, los jóvenes graduados convivían con los periodistas empíricos, muchos de ellos personas con educación superior, que habían abandonado estudios de derecho, historia, literatura u otras disciplinas humanistas para dedicarse a la prensa.

El periodismo era nuevo como profesión universitaria. Cuando comenzó el gobierno de la UP, había apenas cinco escuelas en todo el país, dos de las cuales fueron clausuradas en 1973 por la dictadura ${ }^{4}$. Los preclaros dirigentes del Círculo de Periodistas acompañaron a autoridades como el rector Juvenal Hernández, de la Universidad de Chile, en la tarea de legitimar con la educación superior la labor de la prensa. Estos mismos dirigentes serían los fundadores, en 1956, del Colegio de Periodistas, entidad profesional que tendría su cuota de protagonismo bajo el gobierno de la UP.

Entre 1953 y 1970 se aplicaron varios paradigmas orientadores de los programas de formación de periodistas universitarios. Al comienzo, estuvo la propuesta del "reportero culto", tributaria del modelo anglosajón que a la grupa de la pirámide invertida pretendía establecer una frontera infranqueable entre hechos "sagrados" y opiniones "libres". Más adelante, sin una ruptura radical con el modelo anterior, se ampliaron complementos curriculares que, además de las técnicas, apuntaban a la economía, la historia, la psicología social y otras disciplinas humanistas.

Para el triunfo de Allende y con el antecedente de las reformas universitarias iniciadas en 1967, estaba instalada la tensión entre mallas curriculares que apuntaban al mercado laboral y los afanes de los jóvenes estudiantes de poner su profesión al servicio de la sociedad. Se hablaba así de un "periodista crítico", de un periodismo "comprometido", capaz de ser "la voz de los sin voz", e incluso del "activista revolucionario" (González, 2003).

El gran referente de la comunicación de masas era la prensa escrita, pues orientaba agendas e influía en las opiniones. La radio, valorada como medio de entretención, era elogiada por su inmediatez en la transmisión de contenidos informativos, pero no alcanzaba la gravitación de los diarios. La televisión había llegado a Chile en

4. Correspondían a las Universidades de Chile, Católica de Santiago, Católica del Norte, la sede Valparaíso de la Universidad de Chile y la Universidad de Concepción. Estas dos últimas fueron cerradas por la dictadura. 
1962, con el Mundial de Fútbol, y por ley pertenecía a las universidades y al Estado, lo cual parecía ponerla al margen de las pasiones políticas contingentes, aunque esto cambiaría durante la UP.

Faltaban aún diez años para que la Unesco (Organización de Naciones Unidas para la Educación, la Ciencia y la Cultura) aprobara el Informe MacBride, que develó las profundas desigualdades estructurales en la producción y distribución de contenidos informativos. No obstante, ya se analizaba en Chile la concentración de la propiedad de los medios y sus impactos en términos políticos, económicos y sociales. Uno de los primeros en hacerlo fue el periodista Elmo Catalán. Luego, de una forma más sistemática, Armand y Michelle Mattelart profundizarían en estos aspectos desde la perspectiva de los estudios culturales, para ocuparse también de producciones no periodísticas, pero de impacto masivo, como las telenovelas y las historietas, en trabajos conjuntos con Mabel Piccini y Ariel Dorfman.

La formación universitaria comenzaba a verse confrontada con las teorías y prácticas de la comunicación. Los establecimientos de educación superior advirtieron este desafío y se encaminaron hacia iniciales cambios curriculares en esa dirección, que quedaron virtualmente sepultados por una década con el golpe de Estado y la intervención dictatorial de las universidades.

Cuando se dio inicio al proceso de la Unidad Popular, en el ejercicio del periodismo chileno convivían, a ratos en beligerancia y a ratos amistosamente, las escuelas del empirismo y de la academia. Se admiraba a las grandes plumas de columnistas y cronistas, mientras jóvenes talentos egresados de las universidades se abrían paso sobre todo en la televisión. Estaban, asimismo, los "modelos" que pretendían distinguir a una prensa "seria" de otra "sensacionalista".

La reforma de las universidades también repercutió en las escuelas de periodismo. En el Consejo Normativo Triestamental en la Universidad de Chile se discutían definiciones de fondo sobre el carácter de la profesión y surgían teorizaciones acerca de la "plusvalía relativa" del trabajo del periodista en una identificación con el proletariado.

Era lectura obligatoria un reciente libro del periodista Camilo Taufic, Periodismo y lucha de clases y, en la búsqueda de nuevas propuestas de géneros y formatos periodísticos alejados del molde anglosajón, nos proponíamos materializar propuestas para un nuevo género que queríamos llamar "periodismo dialéctico".

Pero también persistían las tradiciones. Quienes se iniciaban en la profesión en aquellos años tenían que absorber muchas veces ejemplos paradigmáticos de los viejos periodistas empíricos acerca de la creatividad de la llamada prensa popular. El non plus ultra del ingenio era un titular del ya desaparecido vespertino Las Noticias Gráficas (1944-1963) sobre un crimen pasional en un caso de infidelidad: "Matarife benefició a su mujer, por vaca". Esta fascinación por un sensacionalismo 
que toleraba discriminaciones en nombre de lo grotesco adquiriría dimensiones descontroladas en las pugnas periodísticas bajo la UP.

\section{IMPROPERIOS Y SEDICIÓN}

Es cierto que las pasiones políticas se desbocaron por la prensa, en una guerra de titulares descalificatorios al ritmo de la radicalización del enfrentamiento entre el Gobierno y la oposición. Sin embargo, se tiende a caer en una especie de reduccionismo que sobrevalora este aspecto por sobre otros elementos específicos de la lucha de clases que condujeron al quiebre institucional, donde la prensa jugó su rol subordinada a los bandos en confrontación.

En la crítica al papel del periodismo en la polarización que desembocó en el golpe militar se cae con facilismo en la tentación de reducir los análisis a las adjetivaciones ofensivas de los titulares de los tabloides como Clarín, Tribuna o Puro Chile, y las revistas PEC y SEPA, como lo hizo el sociólogo Patricio Dooner (1989). Es cierto que los ejemplos al respecto son interminables. Podría hacerse una eterna exposición de frases ofensivas, a menudo grotescas y de escaso sentido del humor de la prensa derechista sobre el presidente Allende, dirigentes de la UP y el MIR e incluso acerca del líder cubano Fidel Castro durante su prolongada visita a Chile.

Desde la otra trinchera se puede hacer otro tanto. Las descalificaciones de Clarín y Puro Chile en contra de Jorge Alessandri y otros personeros de la derecha, la extrema derecha y la DC fueron también una constante.

La obra de Dooner, publicada en 1989, tiene sin embargo mucho de intento de exculpar tardíamente a la DC, situándola por encima de las pasiones extremistas y obviando su responsabilidad en la desestabilización de la democracia chilena, a la cual contribuyó desde diversos frentes, incluyendo el periodístico, con su diario La Prensa. Para Dooner, el PDC escapaba "del esquema dicotómico de ambos extremos" y, desde esas visiones maniqueas, Eduardo Frei Montalva era para unos "el Kerensky chileno" y para otros el representante de "los intereses de Washington".

Este alineamiento no le hace bien a un estudio que intentó una necesaria revisión del pasado en vísperas del restablecimiento de la democracia formal. Habría sido deseable un esfuerzo más abarcador de parte de Dooner, que dejó fuera de su revisión no solamente a La Prensa, sino también a Las Últimas Noticias y a los vespertinos La Segunda y Última Hora. Además, su análisis de la prensa "seria" se circunscribe exclusivamente a El Mercurio y El Siglo, para poner en evidencia el lenguaje sibilino del primero y juzgar con severidad la terminología militante del diario comunista. Así, reconoce la habilidad mercurial para proyectar una imagen de "neutralidad" que suena como elogio para el medio que más trabajó por la destrucción de la institucionalidad chilena. 
En 2003, con oportunidad del trigésimo aniversario del golpe de 1973, otros dos investigadores, esta vez de la Pontificia Universidad Católica de Chile, retomaron el enjuiciamiento a la prensa "ariete" de derecha e izquierda durante la Unidad Popular, en la misma línea de Dooner. En su artículo, citaron el Informe de la Comisión de Verdad y Reconciliación de 1991, con su condena a los medios de comunicación que extremaron la virulencia verbal y cuyos ataques al adversario sugerían su aniquilamiento físico (Bernedo y Porath, 2003-2004).

Mirado a la distancia y a través de estos juicios condenatorios, puede concluirse que, a la postre, fue la izquierda la más perjudicada por estas guerras verbales de improperios. Lo fue desde el punto de vista político porque su retórica de intimidación del adversario mediante advertencias de una respuesta popular no tuvo el efecto buscado y llevó la lucha a un terreno cómodo para una oposición intransigente. Lo fue también desde una perspectiva cultural, porque se cayó en viejos trucos sensacionalistas que despojaron al proyecto transformador de capacidad de convocatoria en el conjunto de la sociedad.

Pero, a fin de cuentas, ¿fue tan terrible la violencia verbal de los medios? En un escenario de prensa moderada, "neutral y objetiva", ¿se habría evitado el golpe militar? En primer lugar, la propia naturaleza del proceso hacía imposible un sistema mediático de esas características. Diatribas e insultos más o menos, el papel fundamental de la prensa opositora estaba en dotar de racionalidad a los embates contra el gobierno de la Unidad Popular, convencer de que el desabastecimiento era consecuencia de la incapacidad de los funcionarios y no del sabotaje orquestado desde Estados Unidos. En otras palabras, actuar como agente de la sedición, terreno en el cual El Mercurio, con su lenguaje sibilino, fue más efectivo que Tribuna, PEC y SEPA.

Como señala Eduardo Santa Cruz, en la batalla mediática durante la Unidad Popular prevaleció la estrategia de "fragmentación de la realidad" de la prensa de derecha, que convirtió los problemas económicos y sociales de la mayoría de la población en discursos políticos de agitación para alentar las manifestaciones contra el Gobierno. En tanto, la prensa de izquierda siguió atada a viejos moldes y fue incapaz de levantar una estrategia alternativa a la de los medios de derecha, financiados además por el gobierno estadounidense, como ha quedado demostrado sobre todo en el caso de El Mercurio (Santa Cruz, 2014).

Patricio Tupper, periodista chileno y académico universitario radicado en Francia, es autor de uno de los estudios más completos sobre el papel sedicioso desarrollado por medios de prensa opositores al gobierno de Allende, que comprendió una reeditada "campaña del terror" (practicada ya contra el líder socialista en 1958 y 1964) previa a la elección presidencial para pasar a una "guerra psicológica" durante el gobierno de la UP (Tupper, 2003). 
Entre las peculiaridades de la transición chilena hay que destacar que, si bien ha habido juicios y condenas contra quienes violaron los derechos humanos durante la dictadura, los delitos de sedición y complot, ampliamente documentados en investigaciones del Senado estadounidense, permanecen en la impunidad. Es una situación que afecta al periodismo, ya que el principal gestor de la desestabilización externa del gobierno de Allende fue el director y propietario del diario El Mercurio, Agustín Edwards Eastman.

El Colegio de Periodistas expulsó finalmente a Edwards de sus filas en 2015, por graves violaciones a la ética profesional, basándose en la complicidad del diario con montajes represivos bajo la dictadura de Augusto Pinochet. Sin embargo, catorce años antes, el mismo Colegio había desechado una solicitud de sumario ético presentada contra el director de El Mercurio por el periodista Manuel Cabieses, basada en sus gestiones contra Allende en los Estados Unidos ante el entonces presidente Richard Nixon y su secretario de Estado, Henry Kissinger.

\section{ALLENDE Y LA PRENSA}

El Estatuto de Garantías Constitucionales, acordado entre la UP y la DC para que este último partido ratificara a Allende como ganador de la elección presidencial, tenía entre sus puntos principales la preservación de las libertades de prensa y de expresión, con límites muy precisos a la intervención gubernamental en estas materias.

El presidente Allende siempre sostuvo que la firma de ese estatuto estaba en plena consonancia con la vocación democrática de la UP y su propuesta de transición pacífica hacia el socialismo. Y durante su mandato fue rigurosamente consecuente con este planteamiento en lo que respecta a la prensa y a la libertad de expresión.

Fue un mandatario "ultrademocrático", sostienen analistas de izquierda que destacan el pluralismo sin precedentes del espectro comunicacional durante su gobierno, con medios que representaban prácticamente a todas las tendencias políticas, además de confederaciones empresariales y de trabajadores, sobre todo en la radiodifusión. En los diarios, como otra demostración de esta diversidad, la circulación de prensa opositora superaba a la de la prensa progubernamental, con 551 mil ejemplares contra 312 mil $^{5}$ (íbid.).

5. La prensa opositora comprendía a La Tercera, El Mercurio, Las Últimas Noticias, La Segunda, La Prensa y Tribuna. La gubernamental a Clarín, El Siglo, Puro Chile, La Nación y Última Hora. Los datos de circulación excluyen el día domingo, en que aumentaban los tirajes. 
La derecha fue hábil en crear una imagen permanente de amenazas a la libertad de expresión por parte del gobierno. La compra de la quebrada Editorial Zig-Zag por parte del Estado para convertirla en la Editorial Quimantú fue presentada como una operación que pretendía controlar el mercado de revistas, aunque la nueva empresa editora fue, en los hechos, un instrumento de democratización de la cultura, pues publicó miles de títulos literarios a precios irrisorios.

Algo similar ocurrió con la Compañía Manufacturera de Papeles y Cartones, empresa conocida como la Papelera, principal productora de papel de diario. La derecha y la DC lanzaron una furibunda campaña para resguardarla de un supuesto intento de expropiación, bajo el lema “iLa Papelera NO!”, pese a que nunca estuvo en la mira gubernamental la incorporación de esa fábrica al área de propiedad social.

Hay un abundante anecdotario de la consecuencia con que Allende respetó la libertad de expresión, incluso dentro de la propia izquierda. Citemos el recuerdo del exdecano de la Facultad de Economía y Administración de la Universidad de Chile, Roberto Pizarro:

"El Centro de Estudios Socioeconómicos, de la Universidad de Chile, que yo dirigía, había invitado (en octubre de 1971) a un grupo destacado de intelectuales a un seminario sobre la transición al socialismo y la experiencia chilena. Allí estuvieron Paul Sweezy, economista norteamericano, director de la revista Monthly Review, la intelectual italiana Rossana Rosana, resistente antifascista y fundadora de la revista Il Manifesto y Lelio Basso, destacado dirigente del socialismo italiano.

Al término de nuestras actividades, el presidente Allende nos invitó a almorzar a la casa de gobierno. Sentados frente a frente, y en presencia de los invitados al seminario, me pidió que le contara sobre el trabajo realizado. Le dije que las ponencias y discusiones habían sido muy interesantes y, en mi opinión, un aporte para el proceso de transición al socialismo, que vivíamos en nuestro país. Pero, le manifesté mi molestia, porque el diario Puro Chile, de orientación progubernamental, había criticado duramente algunas opiniones, con cierto sesgo izquierdista, de nuestros invitados. Les había otorgado el 'Huevo de Oro'.

Sin vacilar un momento el presidente me dijo textualmente: 'Roberto, yo también he recibido el 'Huevo de Oro', por opiniones e incluso iniciativas que he impulsado. Pero, eso no debe molestarnos. Nunca debes olvidar que nuestra propuesta política, la vía chilena al socialismo, se caracteriza por la más irrestricta libertad de prensa y que nuestro país debe ser un ejemplo de funcionamiento pleno de la democracia”' (Pizarro, 2018). 


\section{ALLENDE Y LOS PERIODISTAS}

En medio del entusiasmo inicial del gobierno de la UP, se realizó en abril de 1971 la Asamblea Nacional de Periodistas de Izquierda. La iniciativa congregó en el auditórium de la Facultad de Artes de la Universidad de Chile a 320 periodistas de los partidos de la Unidad Popular, el MIR e independientes de izquierda, en representación de 640 trabajadores de la prensa de todo el país.

En el discurso inaugural de este gran encuentro, Allende recalcó la posición de su gobierno frente a la prensa:

"Estamos dando la batalla dentro de los marcos de la democracia burguesa y de las leyes que esta democracia burguesa dictó... Y hay que anotar entonces que nos hemos comprometido a respetar la libertad de información. Hay que entender que nosotros no buscamos el monopolio de la información. Y por lo tanto, la lucha que da el gobierno del pueblo es mucho más difícil que la que han dado otros pueblos, que por los caminos de la insurgencia han alcanzado el gobierno y el poder. Nosotros estamos limitados voluntariamente por los compromisos contraídos y por lo tanto, ustedes saben que otros seguirán contando con sus medios de información, que otros seguirán contando con los medios de difusión que les permitirán llevar, tergiversada, la información e interpretar torcidamente las actitudes del gobierno. Por eso la batalla de ustedes, y nuestra batalla, es mucho más difícil”.

El presidente combatió en su intervención "el mito de la objetividad" y se explayó sobre el deber de los periodistas de izquierda, a quienes definió como integrantes del pueblo que han alcanzado un grado de cultura e intelectualidad y cuya tarea es elevar el nivel de las masas en términos de conciencia política. Instó a dar batallas ideológicas, pero también a que la prensa de izquierda levantara campañas vinculadas a las necesidades y a las aspiraciones populares (Allende, 1971).

Armand Mattelart hizo una extensa exposición ante la asamblea, en la que partió advirtiendo los vacíos de estudios marxistas en el dominio de los medios de comunicación de masas y advirtió sobre las estrategias de la prensa burguesa, que puede dar apariencia de democráticos a sus mensajes más sediciosos. Junto con estas advertencias premonitorias, Mattelart llamó a una efectiva democratización de la prensa, no solo en términos de circulación o difusión, sino también de producción. Entregar a las masas la creación de sus propios mensajes, con la capacitación de corresponsales obreros y campesinos, fue una de sus propuestas fundamentales (Mattelart, 1971). 
Al término de la asamblea se eligió una directiva unitaria para dar continuidad orgánica a esta iniciativa. Como presidente fue designado Eduardo Labarca, del Partido Comunista; vicepresidente, Manuel Cabieses, del MIR; y secretario general, Luis Muñoz, del Partido Socialista.

La asamblea comenzó como una gran iniciativa unitaria, pero luego fue diluyéndose en el fragor de las urgencias inmediatas que enfrentaban la prensa y los periodistas. Labarca ${ }^{6}$ recuerda así este proceso:

"Partimos como avión a chorro. La efervescencia era muy grande, porque a los periodistas de los medios que apoyaban al Gobierno - El Siglo, Última Hora, Radio Magallanes, Canal 7, Canal 9, Clarin, etcétera- se sumaba una avalancha de colegas provenientes de los demás medios, incluso los más "tradicionales", simbolizados por los periodistas de ElMercurio que habían formado un comité de la UP con apoyo de Sonia Edwards. A la asamblea llegaron también periodistas de provincia y alumnos de las escuelas de periodismo. El espectro político de la asamblea fue muy amplio, iba más allá de la UP, pues participaban también los colegas de Punto Final y del MIR, y muchos independientes. En las bambalinas todo se negoció entre los representantes de los partidos y movimientos, llegándose al acuerdo de que en la directiva habría dos representantes de cada colectividad política. Los periodistas comunistas nos jugamos en todo momento por un acuerdo amplio y sin exclusiones, además éramos los más numerosos, lo que fue reconocido, de ahí que se aceptara por unanimidad que yo, que era militante del PC, asumiera la presidencia”.

Fue un buen comienzo, que permitió plantearse interesantes tareas, pero que más tarde cayó en la inmovilidad hasta la desaparición de la asamblea por "muerte natural”. Continúa Labarca:

"La Asamblea tuvo mucha repercusión, y entre las principales metas que nos fijamos estuvo el esfuerzo por dar a conocer las realizaciones del Gobierno y poner atajo a la campaña de falsedades — fake news, diríamos hoy — en su contra. Fuimos a informar y expresar nuestro apoyo al presidente Allende, y de ahí en adelante celebramos unas cinco o seis reuniones de la directiva, y es cierto que la organización se fue diluyendo. La verdad es que, además de sacar declaraciones, nuestros esfuerzos por contrarrestar la avalancha 'informativa' contra el Gobierno no tenían futuro, pues los medios siguieron atrincherados

6. Declaraciones de Eduardo Labarca para este artículo. 
cada cual en su postura a favor o en contra; la línea editorial y su orientación la seguían fijando sus propietarios, directores y jefes de redacción, incluso cada uno de los medios progobiernistas tenía su propia línea.

En la asamblea, algunos oradores llamaron a que los periodistas comprometidos con el proceso popular se tomaran los medios enemigos del Gobierno, se puso el ejemplo de las 'coletillas' que en Cuba los periodistas revolucionarios insertaban al pie de los artículos que atacaban a la revolución, e incluso alguien mencionó la necesidad de crear soviets al interior de los diarios de oposición, pero fuera de un amago fallido de huelga en ElMercurio, se trataba de ideas irrealizables, tanto más cuanto que Allende era el primero en reiterar el respeto del Gobierno a la libertad de prensa. Además, en cuanto a los temas propiamente gremiales, la palabra la tenían los respectivos sindicatos y el Colegio de Periodistas. En esas circunstancias, la directiva que yo presidía no tenía agua en la piscina y, por eso, sin un acuerdo expreso, cada uno se fue yendo a lo suyo y yo pasé a dirigir el noticiario de Chilefilms".

Los esfuerzos de organización de los profesionales de la prensa de izquierda, como señala Labarca, tuvieron como referentes al Colegio de Periodistas y a los pocos sindicatos creados en medios o frentes de trabajo. En cuanto a este, la presidencia fue ejercida por la Democracia Cristiana con el apoyo de la derecha, y particularmente del diario El Mercurio, que tenía gran influencia electoral en esta organización profesional.

Le correspondió al Colegio de Periodistas el mérito, al menos nominal, de conseguir durante el gobierno de Allende un sustancial mejoramiento en los sueldos de los profesionales a través de un sistema de aranceles obligatorio para los medios, que establecía escalas de números de salarios mínimos para las diversas categorías (reportero, jefe de sección, jefe de informaciones, redactor, director, etcétera). Una conquista inimaginable en el Chile actual, donde las remuneraciones de los periodistas están al arbitrio de las empresas.

Desde el frente sindical hubo iniciativas durante 1972 para que el gobierno, utilizando la legalidad vigente, caducara concesiones de radioemisoras que operaban abiertamente a favor de acciones sediciosas, pero una vez más se encontraron con la negativa del presidente Allende. En la misma época, el mandatario tampoco vio con simpatía la toma que sus trabajadores hicieron del Canal 9 de la Universidad de Chile, con el fin de impedir la intervención de la rectoría, en manos del democratacristiano Edgardo Boeninger, según las periodistas Gladys Díaz y Lucía Sepúlveda (Díaz y Sepúlveda, 2020). 


\section{GRANDEZAS Y MISERIAS}

En este terreno tan contradictorio, los periodistas de izquierda fueron llamados a trabajar como profesionales y militantes, aun aquellos que no tenían una adscripción partidaria precisa, pero que estaban comprometidos con los proyectos de transformación socialista de la sociedad chilena. Los 29 periodistas y nueve estudiantes de Periodismo, más los veinte trabajadores de la comunicación asesinados o desaparecidos tras el golpe dan cuenta de esto.

Para los periodistas, los mil días de la Unidad Popular fueron una época de claroscuros, de impotencias y realizaciones, donde las propias falencias del proceso generaron iniciativas creadoras y abrieron cauces inéditos aparejados con enseñanzas. La del periodismo fue una lucha de intelectuales orgánicos en un escenario donde las urgencias impedían entender todo lo que estaba en juego en claves de hegemonía y cultura.

Fue una época que dejó como herencia páginas negras para el periodismo, no solo desde la virulencia política, sino también desde un sensacionalismo tributario de la homofobia, en el cual caía con frecuencia la prensa popular que se declaraba de izquierda. El 8 de julio de 1971, el tabloide Puro Chile dedicaba su portada al allanamiento de una residencia céntrica donde la policía practicó varios arrestos. El titular principal decía: "Los maricones presos son estos...", dando a renglón seguido los nombres y apellidos de diez personas. Se podrá decir, como descargo, que eran otros tiempos, pero en esas condiciones eran tiempos que sugerían una marcha hacia atrás de la historia.

Hubo también muchos ejemplos alentadores, como la escuela para dirigentes sindicales creada por el Centro de Estudiantes de la Escuela de Periodismo de la Universidad de Chile. Uno de sus fundadores e instructores fue Luis Durán Rivas, desaparecido por la Dina en septiembre de 1974.

El propio Durán fue, en 1971, junto a otros jóvenes estudiantes de periodismo, arte y otras disciplinas, parte de la "Operación Saltamontes", un proyecto gubernamental de educación popular inspirado fundamentalmente en la pedagogía de Paulo Freire, pero que las autoridades cancelaron al poco andar, luego de una campaña de la prensa derechista que lo denunció como adoctrinamiento marxista. Un episodio poco documentado por los historiadores del gobierno de la UP.

Habría que rescatar también, como sello del gobierno de Allende, la solidaridad internacional que atrajo hacia Chile a latinoamericanos perseguidos por dictaduras. El periodismo fue una de las actividades más beneficiadas por estos éxodos forzados, con casos notables, como la pléyade de excelentes columnistas, redactores, reporteros gráficos y dibujantes que llegaron a la revista Chile Hoy y otros medios. 
Fue también un ejemplo de internacionalismo (otro término devaluado hoy) la llegada a Chile, en el marco de la "Operación Verdad", de un grupo de jóvenes estadounidenses que se propusieron combatir la campaña de falsedades orquestada por la CIA y crearon el Boletín FIN (Fuente de Información Norteamericana). Charles Horman, el joven periodista estadounidense, fusilado el 20 de septiembre de 1973 en el Estadio Nacional y hecho desaparecer con la complicidad de oficiales de la Armada de su país, trabajaba para el FIN. Frank Teruggi, el seminarista y periodista asesinado junto con Horman, era también activo redactor del mismo boletín.

\section{BREVE EPÍLOGO}

No corresponde aventurar conclusiones para este artículo. Las reflexiones que se fueron sumando en su escritura no pretenden arribar a juicios categóricos sobre lo bien o lo mal que lo hicieron los periodistas durante la Unidad Popular, porque, en definitiva, hicieron varias cosas mal y muchas más muy bien. Pero estas últimas, desde la izquierda, pasan por el tamiz de la derrota.

Por tanto, lo que más se puede rescatar es el haber estado ad portas de una profunda transformación de la sociedad y suponer que ese sueño frustrado despertará cuando se pueda volver a hablar de revolución y sentir que es posible hacerla. 


\section{REFERENCIAS}

Allende, S. (27 de abril, 1971). "El discurso de Allende a los periodistas", Punto Final.

Bernedo, P. y Porath, W. (2003-2004). Cómo contribuyó la prensa al quiebre de la democracia chilena, Cuadernos de Información de la Pontificia Universidad Católica de Chile, 16-17, pp. 114-124.

DíAz, G. y SepúlvedA, L. (2020). La batalla de la comunicación durante la Unidad Popular, disponible en https:/ / reddigital.cl/2020/08/27/batalla-los-medioscomunicacion-la-unidad-popular/

Dooner, P. (1989). Periodismo y politica. La prensa de derecha e izquierda en Chile (197073). Santiago: Editorial Andante.

Fernández, O. (1971). Maquiavelo y Lenin. Notas para una teoría política marxista, Santiago: Editorial Nascimento.

GonzÁlez, G. (2003). 50 años de periodismo universitario en Chile: encuentros, desencuentros y desafíos, Comunicación y Medios, 14, pp. 7-16.

Mattelart, A. (13 de abril, 1971). "La prensa de izquierda y el poder popular", Punto Final.

Moretic, Y. (1970), José Carlos Mariátegui: su vida e ideario, su concepción del realismo. Santiago: Editorial Universidad Técnica del Estado.

Moulian, T. (2006). Fracturas. De Pedro Aguirre Cerda a Salvador Allende (1938-1973). Santiago: LOM Ediciones.

Pizarro, R. (2018). "45 años del golpe militar que destruyó la democracia en Chile", disponible en http://www.other-news.info/noticias/2018/09/45-anos-delgolpe-militar-que-destruyo-la-democracia-en-chile/

Santa Cruz, E. (2014). Prensa y sociedad en Chile. Siglo XX. Santiago: Editorial Universitaria.

Tupper, P. (2003). Allende, la cible des médias chiliens et de la CIA (1970-1973), París: Les Editions de l'Amandier. 